\title{
Trifluoperazine Inhibits the Contraction of Cultured Rat Cardiac Cells and the
}

\section{Phosphorylation of Myosin Light Chain}

\author{
IRWIN KLEIN, Department of Medicine, University of Pittsburgh School of \\ Medicine, Veterans Administration Hospital, Pittsburgh, Pennsylvania 15261
}

\begin{abstract}
A B S T R A C T Cultured, spontaneously beating heart cells were used to study the role of calmodulin in regulating cardiac contraction. Trifluoperazine (TFP), an antipsychotic drug that binds to calmodulin, reversibly inhibited myocardial contraction. This effect occurred over a TFP concentration range of $5-100 \mu \mathrm{M}$ with half maximal activity at $\sim 15 \mu \mathrm{M}$ TFP. When the phosphoprotein profile of TFP-treated cells was compared with control cultures, there was a significant decrease in ${ }^{32} \mathrm{P}$ content of the 20,000-D myosin light chain. As measured by two-dimensional gel electrophoresis, the fraction of phosphorylated myosin light chain decreased from $0.31 \pm 0.06$ in control to $0.16 \pm 0.05$ in TFP-treated cells $(P<0.05)$. This inhibition of protein phosphorylation was relatively selective, as two other phosphoproteins $(\sim 41,000$ and $36,000 \mathrm{D})$ were unaffected, and a third protein $(\sim 28,000 \mathrm{D})$ showed an increase in ${ }^{32} \mathrm{P}$ activity. In contrast, the cessation of spontaneous beating by $50 \mathrm{mM} \mathrm{KCl}$ did not reproduce these changes. This inhibition of contraction mediated by TFP associated with alterations in the phosphorylation of certain cardiac phosphoproteins suggests a role for calmodulin and for the myosin light chain in the regulation of cardiac cell contraction.
\end{abstract}

\section{INTRODUCTION}

Phosphorylation of the myosin light chain $(\mathrm{MLC})^{1}$ is an important regulatory step in the control of smooth muscle and platelet contraction. It has previously been

Dr. Klein is a Research Associate of the Veteran's Administration Hospital.

Received for publication 21 July 1982 and in revised form 15 November 1982.

${ }^{1}$ Abbreviations used in this paper: MEM, minimum essential medium; MLC, myosin light chain; TFP, trifluoroperazine. shown that phosphorylation of this protein is mediated by a MLC kinase that requires the presence of both calcium and the calcium binding protein, calmodulin (1-3). Thus, increases in the contractile state of smooth muscle are associated with demonstrable increases in the phosphate content of the 20,000-D MLC (4). The role of MLC phosphorylation in the control of cardiac contractility is less well established $(2,3,5)$. There are reports of increased myosin ATPase activity in association with increased protein phosphorylation (6), whereas other studies show no effect of increased light chain phosphate content on the interaction of cardiac myosin and actin (3).

Trifluoperazine (TFP) is an antipsychotic drug that is capable of inhibiting the intracellular effects of calmodulin. This property accounts for the inhibition of vascular smooth muscle contraction and MLC phosphorylation that is seen after drug treatment $(4,7,8)$. In order to better understand the role of calmodulin (9) and of MLC phosphorylation in the regulation of cardiac muscle, we have examined the effect of TFP on cultured heart cells. This report demonstrates that micromolar concentrations of TFP are capable of reversibly inhibiting the contraction of neonatal rat heart cells in culture. This change in contractility is associated with a decrease in the phosphorylation of the 20,000-D MLC, and an increase in the phosphorylation of a $28,000-D$ protein.

\section{METHODS}

Materials. Eagle's modification of minimal essential media (MEM), essential and nonessential amino acids, supplemental vitamins, penicillin, and streptomycin were obtained from Gibco Laboratories, Grand Island Biological Co. (Grand Island, NY); calf serum and trypsin, from Flow Laboratories, Inc. (Rockville, MD); acrylamide, sodium dodecyl sulfate (SDS), Coomassie Blue, and ampholytes (pH 5-7), from BioRad Laboratories (Richmond, CA); and [ ${ }^{32}$ P]orthophosphoric 
acid and $\left[{ }^{35}\right.$ S $]$ methionine from New England Nuclear (Boston, MA). Plastic petri dishes were obtained from Falcon Labware, Div. of Becton, Dickinson \& Co. (Oxnard, CA) and culture flasks from Corning Glass Works (Corning, NY). Zivic-Miller (Pittsburgh, PA) strain of Sprague-Dawley rats were used in all experiments. TFP dihydrochloride was a gift from SmithKline \& French Laboratories, SmithKline Corp. (Philadelphia, PA). Colchicine, $\beta$-mercaptoethanol, and Nonidet (P-40) were from Sigma Chemical Co. (St. Louis, MO), and 3-isobutyl-1-methylxanthine, from Aldrich Chemical Co., Inc., Milwaukee, WI.

Preparation of heart cells. Heart cells were obtained by trypsinization of 2-4-d-old rat hearts as described by Harary and Farley (10). Hearts were aseptically removed from 12 to 20 neonatal rats, the ventricular tissue finely minced and incubated at $37^{\circ} \mathrm{C}$ in $0.125 \%$ trypsin. The resulting cell suspension was centrifuged at $600 \mathrm{~g}$ for $10 \mathrm{~min}$ and the cell pellet resuspended in MEM supplemented with complete amino acids, $200 \mathrm{mM}$ L-glutamine, $10 \%$ heat inactivated calf serum, vitamins, penicillin, streptomycin, and additional calcium chloride to yield a final concentration of $4 \mathrm{mM}$. This mixed cell population was then incubated in a $120-\mathrm{cm}^{2} \mathrm{Fal}-$ con flask. After $90 \mathrm{~min}$ the nonadherent cells (predominantly myocardial cells) were gently removed and replated at a concentration of $1-2 \times 10^{6}$ cells $/ 3 \mathrm{ml}$ in $60-\mathrm{cm}^{2}$ Falcon dishes that had been previously coated with gelatin.

The culture dishes were incubated at $37^{\circ} \mathrm{C}$ in an atmosphere of $5 \% \mathrm{CO}_{2}: 95 \%$ room air and after $24 \mathrm{~h}$ the media was changed to supplemented MEM with a final calcium concentration of $2.0 \mathrm{mM}$. Cells were observed daily using an inverted stage, phase-contrast microscope from Nikon Inc., Instrument Div. EPOI (Garden City, NY). Within 24 $h$ of plating of the heart cells, spontaneous contractile activity was observed. Rates of contraction were assessed by manual counting for two successive 15-s periods and the average rate calculated. Cultures were maintained at temperatures between 35 and $40^{\circ} \mathrm{C}$. Duplicate counts did not vary by $>5 \%$. Visual observation of the percentage of heart cells, using either the criteria of cell morphology or the presence of contractile activity, demonstrated that between 60 and $90 \%$ of the cells in cultures were muscle cells (11).

Measurement of phosphoproteins. Phosphate incorporation into cultured cell proteins was performed as previously described (12). [ $\left.{ }^{32} \mathrm{P}\right]$ Orthophosphate $(250 \mu \mathrm{Ci} /$ culture dish) was added to MEM prepared without serum. After $1 \mathrm{~h}$ of incubation in this media, the cells were scraped from the dishes into $0.5-1.0 \mathrm{ml}$ of phosphate-buffered saline (PBS) (pH 7.40). Aliquots of the ${ }^{32} \mathrm{P}$-labeled myocardial cells containing between 20 and $50 \mu \mathrm{g}$ of protein were applied to a vertical slab gel electrophoresis system to allow for identification of individual protein subunits containing ${ }^{32} \mathrm{P}$. SDS slab gel electrophoresis using $11 \%$ acrylamide resolving gels overlayered with 5\% acrylamide stacking gels, respectively, were used as described (12). Purified molecular weight standards were routinely used for comparison including myosin purified from 2-d-old rat hearts as described by Shiverick et al. (13).

To analyze radioactively labeled proteins, the gels were dried and exposed to Kodak "X-omat" film (Eastman Kodak Co., Rochester, NY) for varying lengths of time. Specific protein bands were identified by their electrophoretic mobility when compared with standard proteins. The amount of ${ }^{32} \mathrm{P}$ incorporated into individual molecular weight regions of the gel was quantitated by scanning the photographic negtives on an E-C model 910 densitometer, E-C Apparatus Corp., St. Petersburg, FL. Subsequent to the scanning of the autoradiograph, the relative amount of radioactivity in each band was determined by cutting out the individual peaks traced by the densitometer and weighing them (12). This allowed for comparison of the degree of $\left.{ }^{32} \mathrm{P}\right]$ phosphate incorporation into specific molecular weight regions from control and experimental samples when identical amounts of cell protein were applied to a single acrylamide gel. The validity of this method was established by demonstrating a linear relationship of measured densitometer peak volumes from control samples with variable amounts of cell protein applied (range 10-60 $\mu$ g protein).

Because nonmuscle as well as myocardial cells contain the contractile proteins actin and myosin, two-dimensional gel electrophoresis using isoelectric focusing in the first dimension (14) was used to identify the specific phosphoproteins from heart muscle. There are recent reports that the phosphorylated and nonphosphorylated subunits of the MLC can be resolved by two-dimensional gel electrophoresis $(15,16)$. In this series of experiments, heart cells in culture were incubated with $\left[{ }^{35} \mathrm{~S}\right]$ methionine $(100 \mu \mathrm{Ci} / \mathrm{dish})$ for $16 \mathrm{~h}$. Before harvest the cells were washed with PBS, and scraped into an isoelectric focusing buffer containing $5.0 \mathrm{M}$ urea, $2 \%$ Nonidet, $1.6 \%$ ampholytes, pH 5-7 and 5\% $\beta$-mercaptoethanol (14). Approximately $100 \mu \mathrm{g}$ of protein was applied to disc isoelectric focusing gels and run overnight at $400 \mathrm{~V}$. These gels were then equilibrated in $2 \%$ SDS sample buffer and electrophoresed as described with 5\% stacking gel and an $11 \%$ resolving gel (15). By comparison with previously purified neonatal rat heart myosin the Coomassie Brilliant Blue staining spots corresponding to the phosphorylated and nonphosphorylated forms of cardiac $\operatorname{MLC}(\sim 20,000 \mathrm{D})$ were identified. These regions were cut from the gels solubilized with $60 \%$ perchloric acid and $30 \%$ hydrogen peroxide and counted in a Packard model $300 \mathrm{C}$ liquid scintillation counter (Packard Instrument Co., Inc., Downers Grove, IL). The phosphorylated fraction of the 20,000-D MLC was calculated as the percentage of ${ }^{35} \mathrm{~S}$ activity (disintegrations per minute) in the phosphorylated region compared with the total ${ }^{35} \mathrm{~S}$ incorporated into the MLC (phosphorylated and nonphosphorylated forms). All measurements were performed in duplicate and the results expressed as the mean $\pm S E M$. In addition, cultures of heart cells were labeled with $\left[{ }^{32} \mathrm{P}\right]$ orthophosphoric acid for $\mathrm{l} \mathrm{h}$ and the cells were subject to two-dimensional gel electrophoresis as described.

Addition of TFP to cell culture. In order to determine the effects of TFP on cardiac contraction, concentrations of 1-100 $\mu \mathrm{M}$ were added to the culture media. TFP was dissolved in sterile MEM without serum at concentrations ranging from 0.5 to $5 \mathrm{mM}$ and then added to the cell cultures to yield the final concentration as stated in the text. Before drug addition, two base-line heart rates were determined and then again at $2,5,10$, and 20 min subsequent to the addition of TFP. After 20 min, the media was washed twice and replaced with fresh MEM with $10 \%$ serum. When TFP was added after treatment with $1 \mu \mathrm{M}$ colchicine or $10 \mu \mathrm{M}$ isobutylmethylxanthine, the latter agents were preincubated with the cells for $30 \mathrm{~min}$.

In experiments where the effect of TFP upon phosphorylation was assayed, the cells were incubated with $\left[{ }^{32} \mathrm{P}\right]$ orthophosphoric acid or $\left[{ }^{35} \mathrm{~S}\right]$ methionine as described above. $10 \mathrm{~min}$ before harvesting the cells, either TFP at a final concentration of $20 \mu \mathrm{M}, \mathrm{KCl}$ at a final concentration of $50 \mathrm{mM}$, or control MEM was added to the media, and contractile activity was measured 5 and $10 \mathrm{~min}$ later. Cells were then scraped from the dish, the concentration of cell protein determined, and equal amounts of protein applied to $11 \%$ acrylamide gels (11). Quantitation of the amount of ${ }^{32} \mathrm{P}$ in specific protein bands was performed as described. 
Alternatively, cells incubated with $\left[{ }^{35} S\right]$ methionine were similarly treated with TFP or control media, scraped, and subject to two-dimensional gel electrophoresis. The fraction of ${ }^{35} \mathrm{~S}$ radioactivity recovered in the phosphorylated form of the 20,000-D MLC was calculated as described above and compared between treated and control cultures.

\section{RESULTS}

Inhibition of contraction by TFP. Cultures of neonatal rat heart cells demonstrate spontaneous and synchronous rhythmic contractile activity after $48 \mathrm{~h}$ in culture. Control cells maintain this rate for periods in excess of $96 \mathrm{~h}$. When TFP was added to the culture media at 10 and $20 \mu \mathrm{M}$, there was a rapid decrease in the rate of contraction (Fig. 1). The effect of various concentrations of TFP was assessed by measuring the percent of inhibition of heart rate at $5 \mathrm{~min}$ after exposure to the drug. The effect of TFP was dose-dependent over the concentration range of $1-100 \mu \mathrm{M}$ (Fig. 2). Half maximal inhibition occurred at $\sim 15$ $\mu \mathrm{M}$ (Fig. 2). When followed for periods $>10 \mathrm{~min}$, all concentrations of TFP $>20 \mu \mathrm{M}$ led to complete cessation of contractile activity.

The effect of TFP was partially reversible (Fig. 1). $20 \mathrm{~min}$ after exposure to $5,10,20,40$, and $100 \mu \mathrm{M}$ TFP, the drug was washed from the culture media as described (Table I). Recovery from drug treatment was both time and dose dependent. Fig. 1 demonstrates the return of contractile activity for cultures treated with 10 and $20 \mu \mathrm{M}$ TFP. Table I compares the percent return of heart rate for five different TFP dosages. For

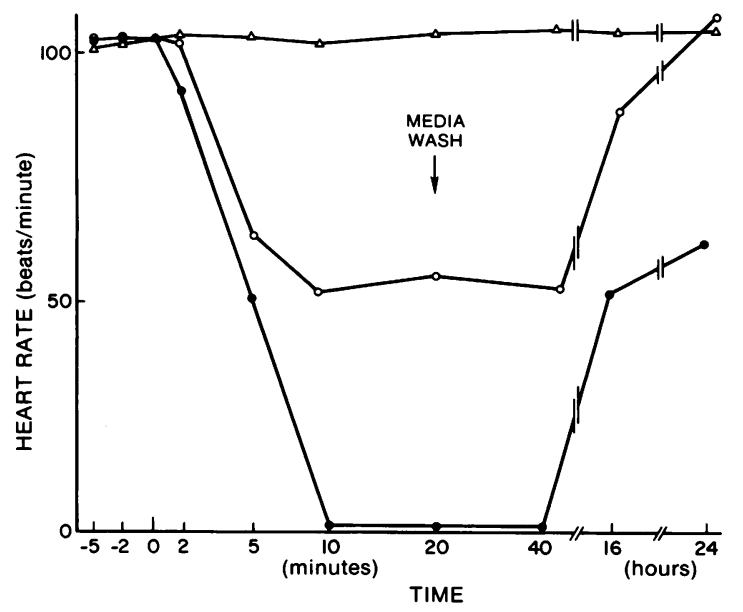

FIGURE 1 Reversibility of the effect of TFP on cardiac contractility. At time zero, TFP at $10 \mu \mathrm{M}(O)$ and $20 \mu \mathrm{M}(0)$ or diluent $(\Delta)$ was added to spontaneously beating heart cells, and contractility assessed at the times indicated. At $20 \mathrm{~min}$, the TFP was removed by washing and replacing all cultures with fresh MEM. Data are means of duplicate determinations.

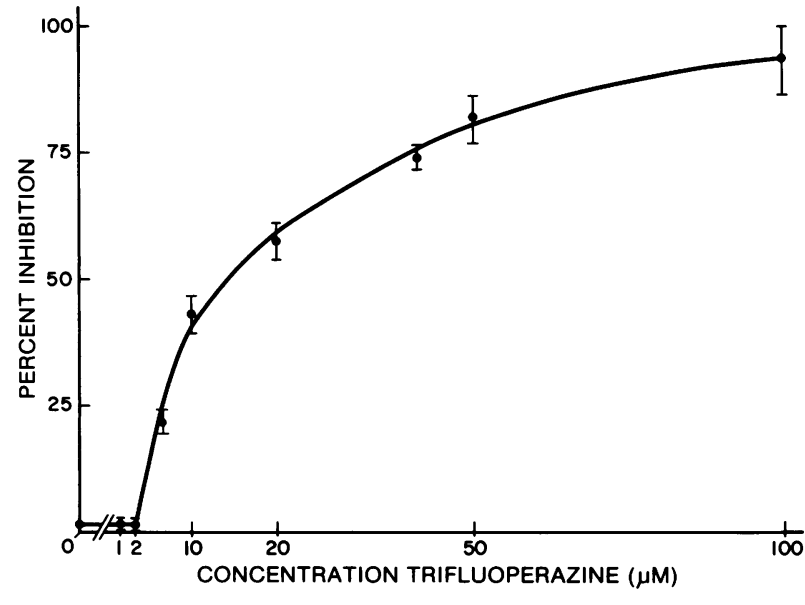

Figure 2 Dose-response curve for TFP upon cardiac contractility. TFP was added to spontaneously beating heart cells and after 5 min the heart rate was measured and expressed as a percentage of the base-line activity. Data are means \pm SEM.

TFP at 5 and $10 \mu \mathrm{M}$, recovery of activity was also measured $2 \mathrm{~h}$ after drug removal and found to be 112 and $55 \%$ of the pretreatment values, respectively. Periods $>24 \mathrm{~h}$ after washout of the drug were not examined. In cultures where the drug was not removed, there was no return of contractile activity. Control cultures to which no drug was added (diluent alone) maintained a constant rate of contractility within a $10 \%$ variation over the $24 \mathrm{~h}$ of observation (Fig. 1).

Pretreatment of heart cell cultures with either isobutylmethylxanthine at $10 \mu \mathrm{M}$ or colchicine at $1 \mu \mathrm{M}$, agents that stimulate contractile activity (15), did not overcome the inhibition produced by 10 or $100 \mu \mathrm{M}$ TFP.

Effect of TFP on protein phosphorylation. Fig. 3 is the autoradiograph from an $11 \%$ polyacrylamide

TABLE I

Recovery of Contractile Activity

\begin{tabular}{ccc}
\hline & \multicolumn{2}{c}{ Heart rate } \\
TFP concentration & (Hours after media wash) \\
\hline$\mu M$ & $16 h$ & $24 h$ \\
5 & 112 & 108 \\
10 & 83 & 106 \\
20 & 50 & 64 \\
40 & 27 & 52 \\
100 & 24 & 41 \\
\hline
\end{tabular}

After the removal of TFP, heart rate was measured and expressed as a percentage of the pretreatment value. Data are means of duplicate determinations. Range of pretreatment heart rate was $\mathbf{9 0}$ 110 beats $/ \mathrm{min}$. 


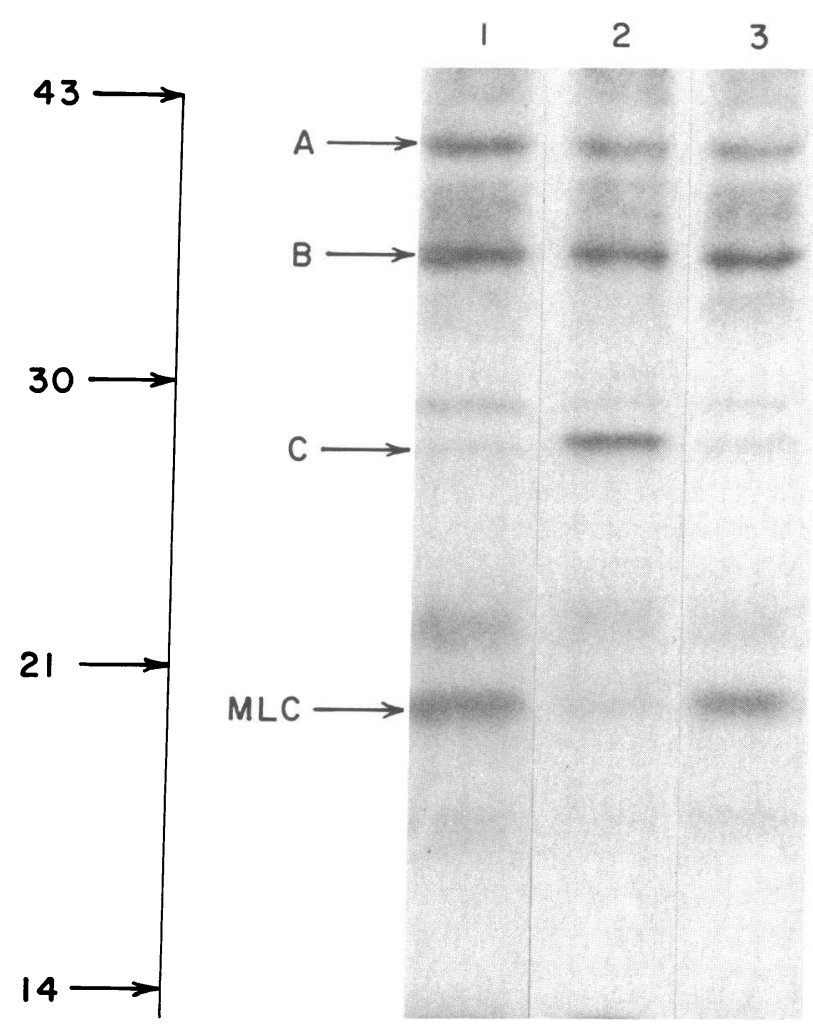

Figure 3 Effect of $20 \mu \mathrm{M}$ TFP on protein phosphorylation. Cardiac cells were incubated with ${ }^{32} \mathrm{P}$, and identical amounts of ${ }^{32} \mathrm{P}$-labeled cardiac cells were applied to one-dimensional SDS-polyacrylamide gels and then subject to autoradiography as described. This is a typical experiment in which lane 1 is a control cell population, lane 2 are cells treated with $20 \mu \mathrm{M}$ TFP, and lane 3 are cells treated with $50 \mathrm{mM} \mathrm{KCl}$. Bands A, B, and C identify three of the major phosphoprotein regions, and MLC denotes the 20,000-D myosin light chain. Left-hand margin indicates migration of standard reference proteins (ovalbumin, 43,000; carbonic anhydrase, 30,000; soybean trypsin inhibitor, 21,000; and lysozyme 14,000-D).

gel of cultured cardiac cells incubated with $\left[{ }^{32} \mathrm{P}\right]-$ orthophosphoric acid as described. Lane 1 is a control cell population that demonstrates a number of discrete phosphoproteins; lane 2 is from cells treated with 20 $\mu \mathrm{M}$ TFP. Three of the phosphoproteins common to both preparations are labeled as $\mathrm{A}, \mathrm{B}$, and $\mathrm{C}$ corresponding to subunit molecular weights of $\sim 41,000$, 36,000 , and 28,000 . These molecular weight estimates are based upon the mobility of four simultaneously run standards proteins (Fig. 3, left margin). An additional $\left[{ }^{32} \mathrm{P}\right]$ phosphate band has identical electrophoretic mobility with a $20,000-\mathrm{D}$ purified rat cardiac MLC. This same ${ }^{32} \mathrm{P}$ band from cultured heart cells also copurifies with rat heart MLC (15) and, therefore, is designated MLC.
Treatment with $20 \mu \mathrm{M}$ TFP for $10 \mathrm{~min}$ before harvesting the ${ }^{32} \mathrm{P}$-labeled cardiac cells both inhibits cell contraction and alters the phosphoprotein profile. As seen in Fig. 3, lane 2, TFP decreased ${ }^{32} \mathrm{P}$ labeling in the region of the MLC. In contrast, the activity of band $C$ was enhanced when compared with control cultures. The degree of phosphate incorporation was determined and found to be the same for bands A and B.

The amount of $\left[{ }^{32} \mathrm{P}\right]$ phosphate incorporated into each of these four bands was quantitated by the use of a scanning densitometer as previously described (12). This technique was used to compare the amount of $\left.{ }^{32} \mathrm{P}\right]$ phosphorus in protein bands of identical electrophoretic mobility from individual experiments. Thus, the degree of protein phosphorylation in Table II is expressed as a percent of the simultaneously run control. Analysis of this data from three separate experiments demonstrates an inhibition of MLC phosphorylation and an increase in phosphorylation of peak C. Peaks A and B were unaffected by TFP treatment.

To determine whether the reduction of MLC phosphorylation was due to treatment with TFP or a function of the associated decrease in heart rate, $50 \mathrm{mM}$ $\mathrm{KCl}$ was used to arrest the beating cells. When added to the culture media in a manner identical to that for TFP $10 \mathrm{~min}$ before harvesting the ${ }^{32} \mathrm{P}$-labeled cells, $\mathrm{KCl}$ produced a complete cessation of contractile activity. An equal aliquot of protein from $\mathrm{KCl}$-treated heart cells was applied to $11 \%$ acrylamide gels and the degree of phosphate incorporation compared with both control and TFP $(20 \mu \mathrm{M})$ cultures (Fig. 3, lane 3 ). Under these conditions the activity corresponding to peaks $A, B$, and MLC were unchanged while there was a $34 \%$ increase in peak $C$ when compared with controls (Table II).

To more specifically identify that the change in $\left[{ }^{32} \mathrm{P}\right]$ phosphate incorporation was due to changes in the phosphate content of the 20,000-D MLC, two-dimensional gel electrophoresis was used. As described above, this was performed with isoelectric focusing in the first

TABLE II

Effect of TFP on Protein Phosphorylation

\begin{tabular}{ccc}
\hline & \multicolumn{2}{c}{$\left[{ }^{\text {[ePIPhosphoprotein activity (\% control) }}\right.$} \\
\cline { 2 - 3 } Peak & TFP! & KCl \\
\hline A & $88 \pm 6$ & $86 \pm 11$ \\
B & $96 \pm 4$ & $114 \pm 6$ \\
C & $225 \pm 46$ & $134 \pm 8$ \\
MLC & $32 \pm 6$ & $108 \pm 5$ \\
\hline
\end{tabular}

- Peaks refer to the autoradiograph bands identified in Fig. 3. † Data are expressed as mean \pm SD $(n=6)$.

$\$$ Data are mean \pm SD $(n=4)$. 
dimension and SDS-polyacrylamide in the second dimension. When cells that had been incubated with $\left[{ }^{35} \mathrm{~S}\right]$ methionine were subject to two-dimensional gel electrophoresis, two discrete areas of activity were observed at 20,000-D (Fig. 4, left). These two spots corresponded identically to the Coomassie Blue staining pattern of previously purified rat cardiac myosin. Further proof that these regions represented the phosphorylated (more acidic) and nonphosphorylated forms of the MLC was provided by ${ }^{32} \mathrm{P}$-labeling of the cells. When cells that had been incubated with $\left[{ }^{32} \mathrm{P}\right]$ orthophosphate were subjected to two-dimensional gel electrophoresis, essentially all of the radioactivity in the 20,000-D region comigrated with the more acidic light chain subunit (Fig. 4, right arrowhead). No ${ }^{32} \mathrm{P}$ activity could be discerned comigrating with the less acidic 20,000-D subunit and similarly no activity was seen to migrate in the region corresponding to the 26,000-D MLC (Fig. 4).

The ability to identify and separate the phosphorylated and nonphosphorylated forms of the MLC then allowed for direct measurement of the extent of light chain phosphorylated. Cardiac cells that had been incubated with $\left[{ }^{35} S\right]$ methionine for $16 \mathrm{~h}$ were scraped and an aliquot of cell protein subject to two-dimensional gel electrophoresis. The Coomassie Blue staining bands corresponding to the previously identified phosphorylated and nonphosphorylated forms of the 20,000-D MLC were cut out of the gel and counted by liquid scintillation spectrometry. Using this technique, the fraction of phosphorylated MLC was calculated to be $0.31 \pm 0.06$ (mean $\pm \mathrm{SEM}, n=6$ ) for con-

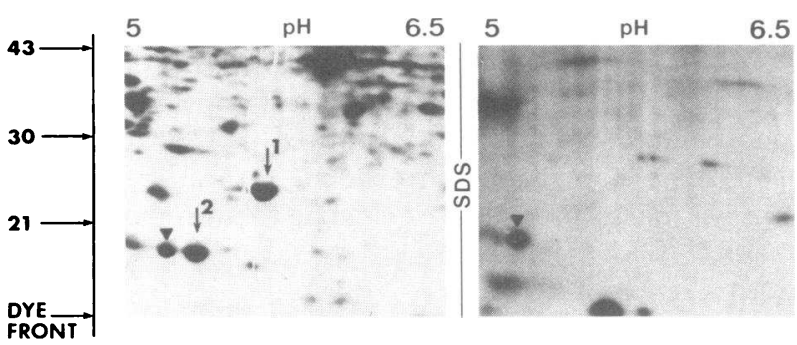

Figure 4 Two-dimensional gel electrophoresis of cardiac cell proteins. On the left is an autoradiogram of cells incubated with $\left[{ }^{35} \mathrm{~S}\right] \mathrm{methionine}$. Arrow 1 indicates the region of migration of purified 26,000-D myosin light chain; arrow 2, the major species of the 20,000-D light chain; and the arrowhead, to the more acidic light chain subunit. These regions correspond exactly to the Coomassie Blue staining of previously purified rat heart myosin. On the right, cells labeled with $\left.{ }^{32} \mathrm{P}\right]$ orthophosphate and subject to autoradiography show activity corresponding only to the more acidic subunit of the 20,000-D light chain (arrowhead). The left hand margin is the migration of reference standard proteins ovalbumin $(43,000)$, carbonic anhydrase $(30,000)$, and soybean trypsin inhibitor $(21,000-D)$. trol heart cells. Before harvest these cells had a mean heart rate of $118 \pm 21$. After exposure to $20 \mu \mathrm{M}$ TFP, there was a prompt decrease in heart rate to $24 \pm 14$ beats/min and the fraction of phosphorylated MLC decreased to $0.16 \pm 0.05$ (mean $\pm \mathrm{SEM}, n=4)$. This decrease in MLC phosphorylation was significant at $P$ $<0.05$.

\section{DISCUSSION}

There is a complex system of control mechanisms that mediates the interaction of actin and myosin and thereby regulates cardiac contractility $(1-3,17,18)$. Although it has been demonstrated that phosphorylation of the MLC is an important regulatory mechanism in smooth muscle, the role of light chain phosphorylation in cardiac muscle has not been defined $(3-5,19)$. Adelstein (1) and Conti and Adelstein (20) working with platelets and Baron et al. (4) in studies of smooth muscle have shown that the phosphorylation of the light chain is catalyzed by a specific kinase that requires the presence of calcium bound to calmodulin as a cofactor for activity.

TFP binds to the calcium-dependent regulator, calmodulin, and has been used to study some of the many reactions mediated by calcium via calmodulin $(7,8)$. Sheterline (21) has shown that TFP can distinguish between the actomyosin interaction regulated by phosphorylation of the MLC and that which is under the control of troponin $\mathrm{C}$ (not calmodulin dependent). In order to better understand the role of calmodulin and the possible role of myosin light phosphorylation in the control of cardiac contractility, the present study used cultured heart cells treated with varying doses of TFP.

The data demonstrate that TFP can reversibly inhibit the spontaneous contractile activity observed in cultured heart cells. In contrast to previous reports (7, 8), we observed TFP inhibition with concentration of the drug as low as $5 \mu \mathrm{M}$ and the dose-response relationship revealed that half maximal inhibition occurred at $\sim 15 \mu \mathrm{M}$ TFP. The onset of drug effect was rapid and was reversible with removal of the drug. TFP treatment was accompanied by a decrease in ${ }^{32} \mathrm{P}$ activity associated with the $20,000-\mathrm{D}$ protein that we have previously identified as a MLC (15). Drug treatment, however, was selective in its effects on $\left[{ }^{32} \mathrm{P}\right]$ phosphate incorporation. Two major phosphoproteins were not apparently altered by TFP, whereas a third protein demonstrated an increase in ${ }^{32} \mathrm{P}$ activity. This latter protein is of interest, and although we have not established the identity of this band, the apparent subunit mol wt of $28,000 \mathrm{D}$ is quite similar to that reported for troponin I in cardiac muscle $(15,19,22)$. 
Our observation that arrest of contractile activity with $50 \mu \mathrm{M} \mathrm{KCl}$ did not produce the same alterations in protein phosphorylation as seen with $20 \mu \mathrm{M}$ TFP suggests that the latter changes were not merely due to an alteration in heart rate. The experimental design used makes it quite unlikely that the changes in ${ }^{32} \mathrm{P}$ labeling activity were due to differences in [ $\left.{ }^{32} \mathrm{P}\right] \mathrm{ATP}$ specific activity, content of MLC, or of the other phosphoproteins in heart muscle.

To further characterize the effect of TFP on MLC phosphorylation, $\left[{ }^{35} \mathrm{~S}\right]$ methionine-labeled cell extracts were analyzed by two-dimensional gel electrophoresis. Similar to previous reports $(16,23)$ this technique allows for the identification and separation of the phosphorylated and nonphosphorylated subunits of the 20,000-D light chain. Thus, by prelabeling cells with $\left.{ }^{35} \mathrm{~S}\right] \mathrm{methionine}$ and then directly counting the activity in the more acidic (phosphorylated) fraction as well as in the nonphosphorylated subunit, a direct measure of the degree of phosphorylation could be made. Under control conditions, $31 \%$ of the light chain chromatographed as the acidic form. This is similar to the percentage of phosphorylated cardiac MLC reported by Holroyde et al. (24). After treatment with $20 \mu \mathrm{M}$ TFP and an accompanying fall in heart rate this significantly decreased to $16 \%$, confirming the observation made with ${ }^{32} \mathrm{P}$-labeled cells.

The finding of an alteration in MLC phosphorylation after treatment of heart cells with TFP suggests a role for the calcium-calmodulin-mediated phosphorylation of MLC in the control of cardiac contractility $(9,19,25)$. In association with the decrease in light chain phosphorylation, we observed an increase in the phosphorylation of a 28,000-D muscle protein. This supports the prior suggestion that the phosphorylation of Troponin I may play a role in the regulation of myocardial contractility $(2,18,26,27)$. The present studies do not distinguish whether the effects of TFP are mediated through alterations in the activity of a MLC kinase (1-3) or alternatively by a change in calcium transport by the sarcoplasmic reticulum $(9,16)$. TFP-mediated changes in contraction allow for the further study of coordinate changes in cardiac phosphoproteins. In the present studies we have used heart rate as a measure of contraction. Many factors can potentially alter heart rate independent of the interaction of actin and myosin. Future studies using direct measurements of heart cell contractility (28) will be required to resolve this question.

Our in vitro observations may explain the in vivo effects of TFP, which has been shown to induce both bradycardia and hypotension when given to psychotic patients under controlled conditions (29). Similar to the present finding, the in vivo effects of TFP on car- diovascular function were reversible after removal of the drug.

\section{ACKNOWLEDGMENTS}

The author thanks Ms. Molly Daood for technical assistance, Ms. Monica Rentz for preparing the manuscript, and Ms. Susan Daley for preparation of the figures.

This work was supported in part by Health Research Services Foundation (Pittsburgh, PA) grant W83.

\section{REFERENCES}

1. Adelstein, R. S. 1980. Phosphorylation of muscle contractile proteins. Fed. Proc. 39: 1544-1546.

2. Stull, J. T. 1980. Phosphorylation of contractile proteins in relation to muscle function. Adv. Cyclic Nucleotide Res. 13: 39-94.

3. Perry, S. V. 1979. The regulation of contractile activity in muscle. Biochem. Soc. Trans. 7: 593-617.

4. Baron, J. T., M. Barany, K. Barany, and R. V. Short. 1980. Reversible phosphorylation and dephosphorylation of the 20,000 dalton light chain of myosin during the contraction-relaxation-contraction cycle of arterial smooth muscle. J. Biol. Chem. 255: 6238-6244.

5. Stull, J. T., D. R. Manning, W. W. High, and D. K. Blumenthal. 1980. Phosphorylation of contractile proteins in heart and skeletal muscle. Fed. Proc. 39: 15521557.

6. Resink, T. J., W. Gevens, T. D. Noakes, and L. H. Opie. 1981. Increased cardiac myosin ATPase activity as a biochemical adaptation to running training: enhanced response to catecholamines and a role for myosin phosphorylation. J. Mol. Cell Cardiol. 13: 679-694.

7. Hidaka, H., T. Yamaki, T. Totsuka, and M. Asano. 1979. Selective inhibitors of $\mathrm{Ca}++$-binding modulator of phosphodiesterase produce vascular relaxation and inhibit actin-myosin interaction. Mol. Pharmacol. 15: 49-59.

8. Kerrick, W. G. L., P. E. Hoar, and P. S. Cassidy. 1980. Calcium-activated tension: the role of myosin light chain phosphorylation. Fed. Proc. 39: 1558-1563.

9. Walsh, M. P., C. J. LePeuch, B. Vallet, J. Cavadore, and J. G. DeMaille. 1980. Cardiac calmodulin and its role in the regulation of metabolism and contraction. J. Mol. Cell Cardiol. 12: 1091-1101.

10. Harary, I., and B. Farley. 1960. In vitro studies of single isolated beating heart cells. Science (Wash. DC). 131: 1674-1675.

11. Norwood, C. R., A. R. Castaneda, and W. I. Norwood. 1980. Heterogeneity of rat cardiac cells of defined origin in single cells of defined origin. in single cell culture. $J$. Mol. Cell Cardiol. 12: 201-211.

12. Klein, I., M. Willingham, and I. Pastan. 1978. A high molecular weight phosphoprotein in cultured fibroblasts that associates with polymerized tubulin. Exp. Cell Res. 114: $229-238$.

13. Shiverick, K. T., L. L. Thomas, and N. R. Alpert. 1975. Purification of cardiac myosin application to hypertrophied myocardium. Biochim. Biophys. Acta. 393: 124133.

14. O'Farrell, P. H. 1975. High resolution two-dimensional electrophoresis of proteins. J. Biol. Chem. 25: 40074021.

15. Klein, I., J. S. Levey, and M. Gondek. 1982. Characterization of the phosphoprotein profile in spontaneous 
beating cultured rat heart cells. Proc. Soc. Exp. Biol. Med. 170: 19-24.

16. Barany, D., D. L. Vander Meu Len, R. F. Ledvora, and M. Barany. 1982. Selective phosphorylation of myosin light chain in intact skeletal muscle. Arch. Biochem. Biophys. 217: 392-396.

17. Adams, R. J., and A. Schwartz. 1980. Comparative mechanisms for contraction of cardiac and skeletal muscle. Chest. 78 (Suppl. I): 123-139.

18. Ebashi, S. 1974. Regulatory mechanism of muscle contraction with special reference to the CA-troponin-tropomyosin system. Essays Biochem. 10: 1-36.

19. Fearson, N., R. J. Solorao, and S. V. Perry. 1976. Changes in phosphorylation of $\mathrm{P}$ light chain of myosin in perfused rabbit heart. Nature (Lond.). 264: 801-802.

20. Conti, M. A., and R. S. Adelstein. 1980. Phosphorylation by cyclic $3^{\prime}: 5^{\prime}$ adenosine monophosphate-dependent protein kinase regulates myosin light chain kinase. Fed. Proc. 39: 1569-1573.

21. Sheterline, P. 1980. Trifluoperazine can distinguish between myosin light chain kinase-linked and troponin Clinked control of actomyosin interaction by $\mathrm{Ca}++$. Biochem. Biophys. Res. Commun. 93: 194-200.

22. Lincoln, T. M., and J. D. Corbin. 1978. Purified cyclicGMP-dependent protein kinase catalyzes the phosphorylation of cardiac troponin inhibitory subunit. (TN-I). J. Biol. Chem. 253: 337-339.
23. DiSalvo, J., E. Gauenstein, and P. Silver. 1978. Ca++ dependent phosphorylation of bovine aortic actomyosin. Proc. Soc. Exp. Biol. Med. 158: 410-414.

24. Holroyde, M. M., D. A. P. Small, E. Howe, and R. J. Solaro. 1979. Isolation of cardiac myofibrils and myosin light chains with in vivo levels of light chain phosphorylation. Biochim. Biophys. Acta. 587: 628-637.

25. Dopp, S. J., and M. Barany. 1979. Phosphorylation of the 19,000 dalton light chain of myosin in perfused rat heart under the influence of negative and positive inotropic agents. J. Biol. Chem. 254: 12007-12012.

26. England, P. J. 1975. Correlation between contraction and phosphorylation of the inhibitory subunit of troponin in perfused rat heart. FEBS (Fed. Eur. Biochem. Soc.) Lett. 50: 57-60.

27. Ray, K. P., and P. J. England. 1976. Phosphorylation of the inhibitory subunit of troponin and its effect on the calcium dependence of cardiac myofibril adenosine triphosphatase. FEBS (Fed. Eur. Biochem. Soc.) Lett. 70: 11-16.

28. Barry, W. T., and T. W. Smith. 1982. Mechanisms of transmembrane calcium movement in cultured chick embryo ventricular cells. J. Physiol. 325: 243-260.

29. Rudenko, G. M., and V. K. Lepakhin. 1979. The major tranquilizers. In Side Effects of Drugs. M. N. Dukes, editor. Excerpta Medica, Amsterdam. 44-45. 